ISSN: 0213-2060

DOI: http://dx.doi.org/10.14201/shhme201533155171

\title{
EL REY FÁVILA, LA REINA FROILIUBA Y LA FUNDACIÓN DE LA IGLESIA DE SANTA CRUZ DE CANGAS (737)
}

\author{
King Favila, Queen Froiliuba and the Founding of the Church \\ of the Holy Cross in Cangas (A.D. 737)
}

Amancio ISLA FREZ

Departament d'Història i Història de l'Art. Facultat de Lletres. Universitat Rovira i Virgili. Avda. Catalunya, 35. E-43002 TARRAGONA. C. e.: amancio.isla@urv.cat

Recibido: 2015-05-29

Revisado: 2015-06-11

Aceptado: 2015-09-28

RESUMEN: Nada relevante nos ha quedado de la fábrica de la iglesia dedicada a la Santa Cruz en Cangas (Asturias). La iglesia fue inaugurada por el rey Fávila, la reina Froiliuba y sus descendientes en el 737. Mucho de lo que sabemos sobre la iglesia y el reino en ese momento depende de nuestra comprensión de la inscripción que conmemora esa inauguración. Apuntamos en este artículo algunas nuevas posibilidades de interpretación, especialmente la influencia del ejemplo del emperador Constantino y la construcción de un imperio cristiano.

Palabras clave: Reino astur; Realeza; Iglesias asturianas; España en la Alta Edad Media; Memoria de Constantino.

ABSTRACT: Nothing substantial remains of the structure of the church dedicated to the Holy Cross in Cangas (Asturias). The church was inaugurated in 737 by King Favila, Queen Froiliuba and their offspring. Much of our knowledge about the church and the kingdom at that time depends on our understanding of the inscription that commemorates its inauguration. This article discusses some new possible interpretations, particularly the influence of Emperor Constantine and the construction of a Christian empire. 
Keywords: Astur Kingdom; Kingship; Asturian Churches; Early Medieval Spain; Memory of Constantine.

SUMARIO: 1 Referencias bibliográficas.

La versión rotense de la Crónica de Alfonso III nos informa de que el rey astur Fávila erigió una iglesia en Cangas ${ }^{1}$. Es la primera noticia que conservamos sobre las actividades edilicias de los monarcas astures. Cangas había sido la residencia del rey Pelayo y el centro de su poder, y, a lo que parece, su hijo y sucesor siguió actuando en ese territorio.

El edificio quedaría integrado en un conjunto del que nuestras informaciones también son muy fragmentarias y escasamente concluyentes. Conservamos testimonios que apuntan a que en Cangas y sus alrededores hubo también otras construcciones de alguna relevancia, pero las noticias al respecto son tardías. El obispo Pelayo de Oviedo, escribiendo a mediados del siglo XII, no solo añadió en la crónica alfonsina la referencia de que el mencionado rey Fávila había sido sepultado junto a su esposa en la iglesia de la Santa Cruz, también interpoló el lugar de enterramiento del rey Pelayo, la iglesia de Santa Eulalia de Velamio², y el de Alfonso I, que situó en el monasterio de Santa María en el territorio de Cangas.

Tenemos alguna descripción antigua del edificio construido por Fávila. Ambrosio de Morales, que realizó su viaje septentrional en 1572, destaca que la edificación es «algo grande» o "no es muy pequeña», fabricada con «sillería lisa», estando formada por una doble estructura, una situada arriba y otra, del mismo tamaño, debajo ${ }^{3}$. Carvallo confirma que la vieja iglesia era de sillería y señala que medía ocho pies de largo por otros tantos de ancho (unos 2,5 × 2,5 m) ${ }^{4}$, estando adosada a una obra posterior. Se abre entonces la probabilidad del derribo de algún sector de la iglesia primitiva y la construcción de una nueva, a la cual quedaría anexada la totalidad o, más probablemente, parte de esa primera iglesia 5 . La iglesia sufrió con posterioridad al viaje de Morales una

1 Rot., 12. Utilizo la edición de GiL, Juan (ed.). Crónicas asturianas. Oviedo: Servicio de Publicaciones, Universidad de Oviedo, 1985. La versión ovetense no menciona su fundación.

2 Otras fuentes insisten en que los monarcas no estaban en principio dentro de la iglesia, sino a los pies y, solo con la ampliación de la iglesia, quedaron sus sepulturas dentro del edificio. (Morales, Ambrosio de. Viage... a los reinos de León y Galicia y Principado de Asturias, ed. de Enrique Flórez. Madrid: por Antonio Marín, 1765, p. 66; Corónica general de España. Madrid: en la oficina de don Benito Cano, 1791, vol. VII, pp. 33-34; CaRVAllo, Luis Alfonso de. Antigüedades y cosas memorables del principado de Asturias. Madrid: por Julián de Paredes, 1695, p. 123). Velamio suele identificarse con Santa Eulalia de Abamia y el enterramiento allí de Pelayo viene siendo considerado legendario; sobre la iglesia, Ríos González, Sergio. «Excavaciones arqueológicas en la iglesia de Santa Eulalia de Abamia (Cangas de Onís), 2005-2006». En Excavaciones arqueológicas en Asturias. Oviedo: Gobierno del Principado de Asturias, 2009, pp. 201-208, quien advierte sobre una iglesia, quizá del siglo Ix, debajo de la actual, cuyas fases más antiguas son del xiII.

3 Esta iglesia de abajo no es sino la subterránea, donde afirma que enterraron al monarca y su mujer (Corónica general de España, vol. VII, pp. 43-47; Viage, pp. 67-68). En el Viage se describe que a esta capilla y altar de abajo hay que descender como si a un pozo se tratara.

4 Antigüedades... del principado de Asturias, p. 124.

5 Esta parte antigua quizá fuera uno de los brazos de la cruz, si, como creemos, el edificio tuvo esta planta (planta de cruz o transepto saliente). Ambrosio de Morales supone que las estructuras subterráneas, el dolmen, son el enterramiento de Fávila (Viage, p. 69). 
refacción importante. En 1632 fue renovado todo el edificio con nuevas afectaciones, cuyo impacto desconocemos.

Ciriaco Miguel Vigil nos proporciona alguna referencia más. Afirma que estaba construida sobre un montículo, «aparentemente artificial $»^{6}$. Nuevas excavaciones, que dirigió el conde de la Vega del Sella, confirmaron la existencia de ese túmulo de cantos rodados que cubría un dolmen, un conjunto sobre el que estaba construido el templo. De hecho, buena parte de quienes han venido estudiando este edificio ya tuvieron la impresión de que la iglesia se levantó precisamente en ese lugar por la previa existencia del dolmen. Y, en efecto, creemos que tienen razón ${ }^{7}$.

En definitiva, carecemos de indicaciones claras sobre el edificio y es difícil que las vayamos a obtener, en buena medida por la última fase destructiva de la iglesia iniciada en 1934 y prolongada en la Guerra Civil. Además, se realizó una obra restauradora que eliminó los edificios demolidos y construyó la obra nueva que tenemos hoy ${ }^{8}$.

En su entorno existe una necrópolis que fue excavada en su día por Vega del Sella, quien halló y describió diversas tumbas, un cementerio que las exploraciones de Martínez Villa han confirmado. Se trata de tumbas con lajas de forma rectangular, cubiertas con cantos y lajas y ocasional sellado con arcilla. La cronología establecida, a partir de la cerámica, permite afirmar la existencia de una fase inicial hacia el siglo viII y, por tanto, puede ser contemporánea de la construcción de la iglesia?.

Afortunadamente otras fuentes, más allá de las interpolaciones pelagianas, afianzan nuestro conocimiento sobre Santa Cruz. La Rotense la define como basilica y califica los

6 Vigil, Ciriaco M. Asturias monumental, epigráfica y diplomática. Oviedo: Hospicio, 1887, vol. I, p. 304. La noticia de que la vieja iglesia era de tres naves la toma Vigil de Caveda y Nava, quien, a su vez, sostiene que proviene de Morales y de Carvallo, en donde no la he encontrado y, en cualquier caso, no parece nada seguro que se refiera al templo levantado en época astur y bien podría aludir a la otra obra de las postrimerías del románico, cuando se produjo una recomposición importante del edificio (CAVEDA y NAvA, José. Ensayo histórico sobre los diversos géneros de arquitectura empleados en España desde la dominación romana hasta nuestros dias. Madrid: Imprenta de Santiago Saunaque, 1848, p. 86). Parece que de esa iglesia quedaba bien poco a mediados del siglo xIX, cuando la estudió José Caveda. La obra de 1632 se encontraba en buen estado al decir de Vega del Sella.

Hay otros dólmenes en la proximidad de iglesias asturianas antiguas (Fernández Conde, Javier. La religiosidad medieval en España. Alta Edad Media (siglos VII-X). Oviedo: Universidad de Oviedo, 2000, pp. 150-151), pero el caso de Santa Cruz de Cangas no es plenamente homologable, pues la iglesia de Cangas se construye encima mismo del dolmen. No cabe, incluso, hacerlo equivaler a Abamia, pues allí el dolmen estaba a unos cuantos metros de la iglesia. Aunque en ocasiones pueda haber una proximidad, la iglesia que nos ocupa es singular por la directa sobreinstalación.

8 García de Castro resume los datos (García de Castro, César. Arqueología cristiana de la Alta Edad Media en Asturias. Oviedo: Real Instituto de Estudios Asturianos, 1995, pp. 511-512). Supone que la parte referida por Carvallo $-8 \times 8$ pies- era la totalidad de la iglesia, algo que me resulta discutible. Destaca su factura en sillería lisa, de la que deduce perspicazmente su originalidad en el conjunto astur. Ante esa originalidad propone unos artesanos inmigrantes procedentes del sur peninsular, pues la técnica era empleada en los edificios hispanogodos; así, la construcción sería «testigo material de la inmigración de gentes foráneas».

9 Vega del Sella, Ricardo [Duque de Estrada y Martínez de Morentín]. El dolmen de la capilla de Santa Cruz (Asturias). Madrid: Museo Nacional de Ciencias Naturales, 1919; Martínez Villa, Alberto. «La necrópolis medieval de la ermita de Santa Cruz (Cangas de Onís)». En III Congreso de Arqueología Medieval Española. Madrid: Asociación Española de Arqueología Medieval, 1989, vol. II, pp. 155-160. 
resultados constructivos como «obra admirable» ${ }^{10}$. Ambos términos los aplicará también a la iglesia de Santa María, construida en Oviedo por Alfonso $\mathrm{II}^{11}$. Por tanto, a pesar de una cierta tendencia a suponerla de un tamaño extremadamente reducido, parece que no debemos exagerar esta nota.

El montículo, según lo describe Vega del Sella, tendría unos 18 x 37 m, aunque es posible que con respecto al del siglo vin hubiera menguado algo por haber sufrido la actividad agrícola en su parte sur. La primitiva iglesia debió englobar al dolmen, cuya cámara mide $2,4 \times 1,28 \mathrm{~m}^{12}$. Una estructura que difícilmente podría quedar cubierta por el edificio de 2,50 x 2,50. Hay que pensar, pues, en un edificio más amplio, ocupando parte considerable del montículo y cubriendo plenamente la estructura subterránea.

Es bien sabido que de la iglesia primitiva se conservó hasta fecha reciente una inscripción que se ha perdido, pero que ha llegado hasta nosotros en diversas transcripciones, en dibujos y en un calco, el de Roberto Frassinelli. Ha sido abundantemente publicada, pero para comodidad del lector la transcribimos ${ }^{13}$ :

\author{
RESVRGIT EX PRECEPTIS DIVINIS HEC MACINA SACRA \\ OPERE EXIGVO ${ }^{14}$ COMTUM FIDELIBUS VOTIS \\ PRESPICVE CLAREAT OC TEMPLVM OBTVTIBVS SACRIS \\ DEMONSTRANS FIGVRALITER SIGNACVLVM ALME CRVCIS \\ SIT CHRISTO PLACENS EC AVLA SUB CRVCIS TROPHEO SACRATA \\ QVAM FAMVLVS FAFFILA SIC CONDIDIT FIDE PROMTA \\ CVM FROILIVBA CONIVGE AC SVORUM PROLIVM PIGNERA NATA \\ QUIBVS CHRISTE TVIS MVNERIBVS PRO HOC SIT GRATIA PLENA \\ AC POST VIVS VITE DECVRSVM PREVENIAT MISERICORDIA LARGA \\ HIC VATE ASTEMO ${ }^{15}$ SACRATA SVNT ALTARIA CRISTO \\ DIEI REVOLVTI TEMPORIS ANNIS CCC \\ SECVLI ETATE PORRECTA PER HORDINEM SEXTA \\ CVRRENTE ERA SEPTINGENTESIMA SEPTAGESIMA QVIN \\ TAQUE
}

10 Basilicam... miro opere construxit (Rot., 12). Emplea basílica para describir otras iglesias y parece entender el término como sinónimo.

11 Miro opere atque forte instructione fabricauit (Rot., 21); como basílica en n. 28.

12 Vega del Sella, El dolmen, p. 21.

13 La ubicación original de la misma sobre el arco de la capilla le otorga toda la importancia de referente fundacional. El original quedó destruido en las vicisitudes bélicas. Utilizo como base la versión de García de Castro, p. 181. Además, empleo las transcripciones de Fernández Conde, F. Javier. "Lugares de culto en Asturias durante la época de la transición». Asturiensia Medievalia, 1993-1994, vol. 7, pp. 31-55; de DíAz y DíAz, Manuel C. "La inscripción de Cangas de Onís». En Asturias en el siglo VIII: la cultura literaria. Oviedo: Sueve, 2001, p. 32; y de Diego Santos, Francisco. Inscripciones medievales de Asturias. Oviedo: Consejería de Educación, Cultura, Deportes y Juventud, 1994, pp. 226-227, n. ${ }^{2} 253$. No pretendo ninguna aportación en la lectura.

14 Fernández Conde lee Ex suo. Se debilitaría más la minimalización arquitectónica.

15 Fernández Conde lee Astemio, y Díaz insiste en una segura lectura Astemo, a pesar de advertir la excepcionalidad del nombre. Ya Fernández-Guerra había leído Astemo (Fernández-Guerra, Aureliano. El libro de Santoña. Madrid: Imprenta de Manuel Tello, 1872, p. 41). Tradujo la inscripción en pp. 108-109. 
La inscripción presenta varios problemas, siendo el más relevante el de la data. La más verosímil solución es la que apuntara Dom Lambert ${ }^{16}$, siguiera Vives y consolidara Díaz. El problema consiste en entender el sentido del verso 11, donde claramente se lee DIEI... ANNIS CCC, siendo esta una manera muy peculiar de dar cuenta de una fecha ${ }^{17}$. Sin embargo, el sentido general puede explicar el conjunto. Lo que propone el epígrafe es datar por los días del año en curso, por los años de la era transcurridos y por la edad del mundo. La lápida, por tanto, proporcionaba diversos modos de establecer la fecha. Lo que sucede es que tal comportamiento no es casual. La datación combinaba un componente de carácter apocalíptico, haciendo referencia a la sexta edad, la última del mundo, aunque la frase no precisa qué año corría de esa etapa terminal ${ }^{18}$. Es probable que la referencia a los días trascurridos buscara reforzar el componente trinitario, pues era sencillo traducir los trescientos días a las tres personas idénticas de la trinidad. Esta voluntad podría ser aún más clara en un templo dedicado a la santa cruz: una fecha y un modo de redactarla -con la triple C- que podría, representando la idéntica divinidad de las tres personas, resaltar la condición divina de Cristo y su perfecta humanidad. No se utiliza, en cualquier caso, la habitual calendación, lo que implica alguna voluntad de expresar una propuesta concreta. Lo que tampoco aparece -y conviene llamar la atención sobre el fenómeno- es la datación por el reinado del monarca, más aún porque era el primer año del rey Fávila. Por tanto, mientras que el recién inaugurado rey se desvanece en la datación, se insiste primero en un día concreto del año en curso, luego en la marcha hacia el fin de los tiempos y, finalmente, se data por la era ${ }^{19}$. Todo el conjunto revela originalidad y reclama centralidad en la explicación.

Otro elemento digno de tener en cuenta es la noticia del verso 4, que García de Castro traduce como «mostrando figuradamente el signo de la Santa Cruz» y Díaz y Díaz como «haciendo gala de mostrar en figura la señal de la cruz salvadora» ${ }^{20}$. Entendemos la frase en el sentido de que habría de hacerse visible en el templo la forma de la cruz, quizá

16 Lambert, A. "Astère». En Dictionnaire d'Histoire et de Géographie ecclésiastiques. Paris: Letouzey et Ané, 1930, vol. IV, pp. 1164-1165.

17 Fernández Conde, «Lugares de culto», p. 49 y nota 40. Señala los problemas de concordancia y está tentado a afirmar una posible manipulación o reelaboración de la última parte del epígrafe. Por mi parte creo que solo la propia excepcionalidad del epígrafe explicaría la impericia del lapicida en la construcción de la frase. Todo ello redunda en la importancia de lo que se quería señalar.

18 Los cálculos más extendidos proponían que el último año de la sexta edad sería el 800. Sobre estas cuestiones, vid., GiL, Juan. «Los terrores del ańo 800». En Actas del Simposio para el estudio de los códices del "Comentario al Apocalipsis» de Beato de Liébana. Madrid: Joyas Bibliográficas, 1978, vol. I, pp. $217-247$. También Barbero, Abilio y Vigil, Marcelo. La formación del feudalismo en la Península Ibérica. Barcelona: Crítica, 1978, pp. 249-258. Afirmación de esta edad la hallamos en la tradición visigoda, pero también en la romana, como, por ejemplo, en Lactancio (Lactancio, Lucio C. Divinae Institutiones, ed. S. Brandt. Viena: F. Tempsky, 1890, Corpus Scriptorum Ecclesiasticorum Latinorum, vol. 19, VII, 14).

19 No hay mucho con lo que comparar, pero en el epígrafe fundacional de la iglesia de San Juan de Baños (Vives, José. Inscripciones cristianas de la España romana y visigoda. Barcelona: Consejo Superior de Investigaciones Científicas, $1942=I C E R V$, n. ${ }^{\circ}$ 314) se menciona el año del reinado de su fundador. Se trata de una inscripción también con una compleja lectura.

20 García de Castro, Arqueología cristiana, p. 182; Fernández Guerra la tradujo como «manifestando simbólicamente la señal de la Santa Cruz» (El libro de Santoña, p. 108). 
en la planta, aunque también cabe suponer que hubo alguna cruz en lugar destacado ${ }^{21}$. Ya hemos señalado cómo lo poco que sabemos del edificio no contradice la posibilidad de que tuviera esa forma en planta.

En este mismo orden de cosas se encuentra la reiteración en el concepto de la cruz, que aparece en el verso 4: signaculum alme crucis (el signo de la cruz salvadora) y en el verso 5: aula sub crucis tropheo sacrata (aula consagrada bajo el trofeo de la cruz). La idea del tropaeum refuerza la percepción de la victoria que la cruz proporciona. Se entiende que se trata, en general, de la redención, de la victoria de Cristo y, por tanto, de los fieles sobre la muerte y el pecado ${ }^{22}$. Lo que sucede es que esa cruz y su vexillum tenían también una tradición asociada a la victoria en la tradición política desde el Imperio romano cristiano.

En la inscripción aparece recogido el nombre del monarca fundador, Fávila. Sin embargo, hay elementos extraordinarios en esa presencia regia. Junto al rey se menciona por su nombre a su esposa, Froiliuba, y también se alude a sus hijos. Así, en plural, lo que quizá, ya de por sí, revele por qué no fueron explicitados sus nombres, al exigir un aumento y complicación de los versos. El rey, por su parte, recibe el apelativo de famulus. El título procedía del ámbito cristiano y lo encontramos con alguna frecuencia, tanto en inscripciones, sobre todo las funerarias ${ }^{23}$, como en otros documentos escritos. Sin embargo, no formaba parte del repertorio regio que emplearon los monarcas visigodos ${ }^{24}$. $\mathrm{Al}$ contrario, es una novedad astur.

Quien introdujo y desarrolló el empleo del calificativo famulus ligado al poder fue el entorno del emperador Constantino. Tanto en griego como en latín, el emperador asumió un vocabulario de servicio que, en principio, pretendía destacar su condición de servidor de Dios. El título tenía resonancias mosaicas ${ }^{25}$ y Eusebio de Cesarea lo había empleado profusamente en la idea de reforzar el vínculo del emperador con Moisés, el legislador y liberador del pueblo judío, un personaje elegido por Dios para liderar a los suyos $^{26}$. No obstante, Constantino parece haberlo usado en etapas anteriores a las de sus

21 M. C. Díaz propuso que la frase «alude a la forma singular de la planta de la iglesia», p. 39. Como ejemplos de grandes cruces hay que recordar la cruz presente en la Basilica Helenae de Roma o la reproducida en el ábside de Santa Pudenciana de Roma, quizá remitiendo a la entregada por Teodosio II a la basílica del Gólgota en Jerusalem.

22 Crux ista triumphus erat. Tropaeum enim insigne: triumphus autem devicti hostis indicium (Rufino, Commentarius in Symbolum Apostolorum, 14; PL, vol. 21, col. 353).

23 Término no necesariamente ligado al clero. Así se emplea para conmemorar a Silvano, famulus Dei, que murió a los dos años (HE, 20545) o a Orania, que murió con tres (HE, 24846).

24 Díaz y Díaz estudió el tema en varias oportunidades: DíAz y DíAz, Manuel C. «Titulaciones regias en la monarquía visigoda». Revista Portuguesa de Història, 1978, vol. XVI, pp. 133-141; «Más sobre epítetos regios en la Hispania visigoda». Studi Medievali, 1978, vol. XIX, pp. 317-333; «La lengua institucional en la Hispania de los siglos VI-XI». En Ideologie e pratiche del reimpiego nell'Alto Medievo. Spoleto: Centro Italiano di Studi sull'Alto Medioevo, 1999, pp. 435-458.

25 Como famulus Domini aparece en numerosas ocasiones en el libro de Josué (por ejemplo: 1, 13; 1 , $15 ; 8,31 ; 12,6)$.

26 Hollerich, Michael J. «The Comparison of Moses and Constantine in Eusebius of Caesarea's Life of Constantine». Studia Patristica, 1989, vol. 19, pp. 80-85. Drake, Harold A. Constantine and the Bishops. The Politics of Intolerance. Baltimore: Johns Hopkins University Press, 2002, pp. 376-378. Rufino lo traduce como famulus Dei (Historia ecclesiastica, en Eusebius Werke, ed. de Eduard Schwartz y Theodor Mommsen. Leipzig: J. C. Hinrich'sche Buchhandlung, 1908, vol. II, IX, 9, 8). 
vínculos con Eusebio. En la carta que dirige a los obispos que acaban de revisar el problema donatista en Arlés en 314, se denomina a sí mismo famulus ${ }^{27}$. Es muy probable que estas propuestas procedieran de Lactancio, quien actuaba en la corte de Constantino como mentor de su hijo Crispo y quien desarrolló una notable influencia en aquellos años. Lactancio había insistido en este concepto famular para definir las relaciones del individuo con $\operatorname{Dios}^{28}$.

Precisamente la percepción generalizada sobre Constantino en época visigoda, la que manifiesta Isidoro de Sevilla sobre su caída en la herejía, debió constituir una fuerte barrera contra la utilización de epítetos desarrollados por este emperador ${ }^{29}$. Eso no parece haber inquietado a la corte astur, en donde el término se empleó para describir entre otros a Pelayo y, como vemos, al propio Fávila ${ }^{30}$.

El paralelismo de Pelayo y Moisés había sido también resaltado en el ciclo cronístico astur, en donde la victoria de Covadonga y, especialmente, el episodio del sepultamiento de los musulmanes por la montaña, había sido comparado con el destino del faraón y los suyos al cruzar el mar Rojo. Sin embargo, no se trata solo de la proximidad de dos episodios, más aún si el relato de uno se ha construido sobre el otro. Lo relevante es la voluntad de aproximar las dos realidades. Dios, como muestran ambas narraciones, obra a favor de su pueblo frente a quienes lo persiguen. Moisés había sido llamado famulus ${ }^{31}$ y el episodio del mar Rojo con la muerte del faraón había sido comparado por Eusebio/ Rufino con la victoria de Constantino y el ahogamiento de Majencio ${ }^{32}$. El cronista astur señala las maravillosas acciones divinas -los magnalia Domini del relato bíblico-, el milagroso castigo de quienes persiguen a la Iglesia. El paralelismo tendrá gran desarrollo, pero es fácil que esta percepción estuviera ya presente en medios astures antes de que se consolidaran en el reino las lecturas más ligadas al mozarabismo ${ }^{33}$.

En realidad, el éxito de Covadonga, según es desarrollado por la Crónica de Alfonso III, tendría que ver, además, con el retorno de los proyectiles lanzados en la batalla,

27 von Soden, Hans. Urkunden zur Entstehungeschichte der Donatismus. Bonn: Markus \& Weber, 1903 n. $^{\circ}$ 18. Eusebio conoció a Constantino en el contexto de Nicea en 325.

28 Digeser, Elizabeth DePalma. The Making of a Christian Empire. Lactantius and Rome. Ithaca: Cornell University Press, 2000, esp. p. 171; Heım, François. «L'influence exercée par Constantin sur Lactance: sa théologie de la victoire». En Fontaine, Jacques y Perrin, Michel (eds.). Lactance et son temps. Recherches actuelles. Paris: Beauchesne, 1978, pp. 55-74.

29 Había sido bautizado en el arrianismo por Eusebio de Nicomedia poco antes de su muerte (Vita Constantini, IV, 62; Cameron, Averil y Hall, Stuart. Eusebius, Life of Constantine. Oxford: Clarendon Press, 1999).

30 Isla Frez, Amancio. "El adopcionismo y las evoluciones religiosas y políticas en el reino astur». Hispania, 1998, vol. 58, n. ${ }^{\circ}$ 200, pp. 971-993.

31 Figura como seruus en algún momento y como famulus Domini en Josué, 1, 13; 1, 15; 8, 31, etc. También así aparecerá el propio Josué: Iud., 2, 8. Por supuesto se transmite a la condición davídica: 1 Reg., 8, 25.

32 Rufino, Historia ecclesiastica, IX, 9. Allí Constantino aparece como therápon o famulus Dei (8).

33 Recuérdese que el mensaje de Oppas es semejante al de los israelíes que dudan: melius erat servire eis, quam mori (Ex., 14, 12). Buena parte del relato se está apoyando en este referente bíblico. También los restos de los musulmanes son visibles, como los cuerpos del ejército del faraón (Ex., 14, 31). Lactancio había sentido esta influencia al referirse al puente Milvio. Lo señala Moreau, quien recuerda el influjo de Ex., 17, 11 sobre: manus dei supererat aciei (de 44, 9 en Moreau, Jacques. Lactance. De la mort des persécuteurs. Paris: Éditions du Cerf, 1954, vol. II, p. 442). 
que, sin afectar a Pelayo y los suyos, recaerían sobre los musulmanes. Es aquí cuando se producen las dos terceras partes de las bajas de los atacantes. Sería una situación similar a la que tuvo lugar en la batalla del río Frígido, en la que las jabalinas de los enemigos de Teodosio cayeron, por efecto de un viento milagroso, sobre quienes las habían arrojado ${ }^{34}$. Este modelo se solapa al del desplome de la montaña, preciso, no obstante, para homologar su victoria a la de Moisés, por el paralelismo de una masa -ahora de tierra- que caería engullendo a los enemigos. La victoria de Covadonga, así entendida, se presentaba como una intervención divina contra quienes persiguen al pueblo de Dios. Además, había otros simbolismos, pues en la tradición cristiana se había parangonado la victoria del mar Rojo con la Resurrección, tal y como ocurre en el Exultet de Venancio Fortunato.

La iglesia de la Santa Cruz fue consagrada por un obispo, un vates. El término no es habitual, pero es empleado aquí y allá, tanto en la epigrafía como en otros textos poéticos, para referirse al obispo ${ }^{35}$. En la tradición hispana aparece alguna vez con este mismo sentido $^{36}$. El obispo puede llamarse Astemo - un nombre desconocido- o ser el algo más frecuente Asterio. En cualquier caso, el personaje no nos es transmitido por otras fuentes e ignoramos la sede de la que era titular.

Las crónicas astures datan la muerte de Pelayo en Cangas en el año 737 y le otorgan diecinueve ańos de reinado ${ }^{37}$. No mucho después se inauguraría la iglesia de la Santa Cruz, realizada, según la inscripción, en ese mismo año 737 . Hemos de suponer, por tanto, que el edificio debió de construirse durante el momento final del reinado de Pelayo y concluirse a su muerte. Es probable que los de Cangas tuvieran presente el ejemplo del rey David, que no llegó a construir el templo, que sí que levantaría su hijo Salomón ${ }^{38}$. Una constatación que podía reforzar la idea de la definición de una nueva ciudad, núcleo de un nuevo reino. El protagonismo de Fávila en esta edificación es palmario y, probablemente, allí manifestaría su voluntad de resaltar algunas de sus propuestas políticas. Lo que queda de esos planteamientos está en el epígrafe, en donde presumimos que se formularían ideas con intenciones de futuro - por ser el inicio del reinado-, pero que, quizá, ya estaban presentes en momentos anteriores del reino.

34 Rufino, Historia ecclesiastica, XI, 33. Es interesante que Jonás de Orleans, al insistir en la milagrosa victoria de Constantino, destaca el papel de la cruz como protectora frente a las flechas del enemigo (JonÁs De Orleans. De cultu imaginum, II, PL, 106, col. 346). La asociación, aunque peculiar, remite al desarrollo del Frigidus y de Covadonga.

35 Du Cange recuerda (voz Vates) varios ejemplos, entre ellos la inscripción funeraria del papa Juan II y le da el significado de episcopus. Ildefonso de Toledo se había referido a Leandro e Isidoro de Sevilla cono ex ordine vatum (ICERV, n. $\left.{ }^{\circ} 272\right)$.

36 El obispo Juan de Tarragona a principios del siglo vi es llamado mirificus vates (ICERV, n. ${ }^{\circ}$ 277). Una inscripción emeritense nos informa de una reparación en una iglesia que se data sub Horontio uate, proporcionando la era del 661, lo que nos confirma que fue el obispo de Mérida de este nombre el que asistió a algunos concilios de ese tiempo (ICERV, n. $\left.{ }^{\circ} 358\right)$.

37 Existe una tradición que supone que Pelayo murió un 18 de septiembre, viernes, pero el de 737 cayó en jueves. Garibay menciona la data sin apuntar su origen (GARIBAY, Esteban de. Compendio historial. Barcelona: por Sebastián de Cormellas, 1628, vol. I, p. 336). Quizá sea un error surgido de las cifras que proporciona algún catálogo regio sobre la duración del reinado de Pelayo (menses VIIII, dies XVIIII-según el códice rotense de la Albeldense, Alb., XVa-) o, tal vez, sea la fecha de la muerte de Fávila, pues en 739 el 18 de septiembre sí fue viernes.

$$
38 \text { Reg., 8, } 17 .
$$


AMANCIO ISLA FREZ

EL REY FÁVILA, LA REINA FROILIUBA Y LA FUNDACIÓN DE LA IGLESIA DE SANTA CRUZ DE CANGAS (737)

Una indicación muy firme proviene de la propia fecha de erección de este templo dedicado a la cruz. Sabemos que la victoria de Constantino sobre Majencio, que tuvo lugar en el puente Milvio, a las afueras de Roma siguiendo el recorrido de la vía Flaminia ${ }^{39}$, se produjo el 28 de octubre del 312, cuando Majencio conmemoraba su sexto acceso al imperio $^{40}$. Lactancio cuenta que, la noche previa a la batalla, Constantino había tenido un sueño en el que se le mandó representar el celeste signum Dei en el escudo de sus soldados. La versión de Eusebio de Cesarea es diferente, pues se refiere, por una parte, a un portento visible para muchos, sucedido a mediodía, percibiéndose una señal en el cielo, el trofeo de la cruz, con la conocida inscripción (in hoc vince) y, además, a un sueño esa misma noche en el que Cristo mandaba al emperador poner esa señal en el estandarte, el lábaro ${ }^{41}$. Es bien conocida la importancia que los cristianos acabaron otorgando a la cruz y a su despliegue por el ejército victorioso, por más que sea discutible la efectiva y generalizada presencia del símbolo en los ejércitos de Constantino.

Lactancio, sin embargo, proporciona la data del seis de las calendas, lo que nos llevaría al 27 de octubre. Se trata de un error, pero quizá aún más indicativo para nosotros, pues parece remitirnos a quien fue la fuente de los de Cangas ${ }^{42}$. Obviamente, no es una coincidencia que una iglesia dedicada a la Santa Cruz fuera sacralizada el día en que se conmemoraba la victoria del puente Milvio o, más bien, la de la Cruz sobre el paganismo, es decir, como se había acabado presentando la derrota de Majencio a manos de Constantino ${ }^{43}$. Se anudaban, pues, las referencias a la victoria constantiniana con las referidas a la cruz. La efeméride apuntaba al inicio de un nuevo tiempo con un nuevo líder, frente a una época anterior que queda arrumbada.

Nuestras fuentes sobre el tema del hallazgo de la cruz y la erección de los edificios cristianos de Jerusalem coinciden en destacar que el emperador Adriano había construido un templo dedicado a Venus en el mismo espacio en el que se levantarán luego los edificios que conmemoraban la crucifixión y la resurrección, el Martyrium y la Anástasis. Es posible, además, que hubiera una estatua dedicada a Júpiter en el mismo lugar del Gólgota ${ }^{44}$.

39 Es sabido que Aurelio Víctor daba Saxa Rubra como primer escenario de la batalla (Aurelio VícToR. De Caesaribus, 40, 23; ed. Franz Pichlmayr. Leipzig: Teubner, 1983 reimp).

40 Inminebat dies quo Maxentius imperium ceperat, qui est a.d. sextum Kalendas Nouembres, et quinquennalia terminabantur (De mortibus persecutorum, 44, 4; Lactance. De la mort des persécuteurs, I, p. 125).

41 Lactancio, 44, 5; Eusebio, Vita Constantini, I, 28 y 29; en Eusebio la visión y el sueño son más imprecisos cronológicamente. Rufino traduce que el emperador vidit per soporem el signo de la cruz, signum crucis, y a los ángeles diciendo el mensaje (Historia Ecclesiastica, IX, 9).

42 Podemos confirmar el día de la batalla gracias al Calendarius Philocali que señala en el día 28 de octubre la evictio tyranni y al día siguiente el adventus divi, refiriéndose respectivamente al destino de Majencio y a la entrada en Roma de Constantino (CIL, I, p. 352). Moreau cree que se trata de un error de Lactancio (De la mort des persécuteurs, vol. II, pp. 432-433). El error parece haber sido transmitido a los de Cangas; con todo es posible que optaran por el domingo más próximo a la conmemoración.

43 Agustín de Hipona. De civitate Dei, V, 26. Es posible que el realce que se quiso dar a esta datación explique el vacío de una buena parte de esa línea, en torno a un tercio (vid. Fernández Conde, «Lugares de culto", p. 50).

${ }_{44}$ Lo afirma Jerónimo, aunque Eusebio silencia el asunto (Drijvers apunta algunos de los motivos de Eusebio para este silencio; Drijvers, Jan Willem. Helena Augusta. The Mother of Constantine the Great and the Legend of Her Founding of the True Cross. Leiden: Brill, 1992, p. 89). La presencia de un Júpiter en uno de los foros de Aelia Capitolina parece aceptable. 
La actuación de Adriano será presentada por los escritores cristianos como resultado de una voluntad de suprimir la huella del cristianismo, un caso evidente de borrar toda memoria de Cristo ${ }^{45}$. De manera que la construcción de época constantiniana exigió un vaciamiento de tierras y, a lo que parece, también un nuevo acopio de materiales que cubrieran los desniveles y las huellas del templo pagano ${ }^{46}$. La realización de este proyecto buscaba generar una Nea-Jerusalem que borrara los restos del paganismo y continuara la tradición romana de erradicar también los del judaísmo ${ }^{47}$. Esta dinámica de superponerse a templos paganos la encontramos en otros edificios cristianos y en relatos con una carga ejemplarizante, como el referido al Serapeon de Alejandría contado por Rufino.

La basílica de Cangas se asentó también sobre una estructura previa que, probablemente, entendieron como un lugar del paganismo. Se erigió o reforzó, además, un montículo como el del Gólgota ${ }^{48}$. La reconstitución del lugar y la construcción dejaban bien claro la victoria de la cruz sobre el pasado pagano. Dicho de otra manera, en las proximidades de la corte regia había la voluntad de erigir un edificio que testimoniase la victoria y el favor divino en la constitución de un reino cristiano, liderado por una familia que resaltaba su paralelismo con la constantiniana.

Otra posibilidad no contradice la anterior y hasta es posible que fuera desarrollándose con el tiempo. Con este modelo de «templo victorioso" pudo confluir el propio hecho de que la iglesia de Jerusalem englobaba la tumba de Cristo, una gruta ${ }^{49}$. Otros modelos basilicales en Roma también se desplegaban sobre tumbas, como la que se levanta en el Vaticano sobre los restos del apóstol Pedro. Si el dolmen fue interpretado como lugar de enterramiento imaginario o real, la nueva basílica tenía mayor motivo para ubicarse sobre el conjunto megalítico.

La inventio de la cruz en Jerusalem desarrolló una conmemoración que acabó centrándose en la fiesta de la Exaltatio crucis, el 14 de septiembre. La viajera Egeria que visitó esas tierras en la década del 380 narra el contenido de la celebración con la adoración de

45 Vita Constantini, III, 26; Jerónimo, Ep. 58, 3 (ed. Hilberg, Corpus Scriptorum Ecclesiasticorum Latinorum, 54, Viena-Leipzig, 1910). Además, Vita Constantini, III, 28. Algo por el estilo se achacaba también a la intervención pagana en Mamre, donde Eutropia, la madre de Fausta, se quejaba de cómo estatuas y altares paganos se levantaban en el lugar en que Abraham había recibido el mensaje divino (sobre el lugar del terebinto, Gen., 13, 18). Esta presencia de cultos paganos en Mamre se ha confirmado arqueológicamente, pues se ha hallado una estela dedicada a Hermes y una cabeza de Dionysos (TAYLOR, Joan. Christians and the Holy Places. Myth of Jewish-Christian Origins. Oxford: Clarendon Press, 1993, pp. 88-89). Sobre la iglesia del Santo Sepulcro, además, CoüAsnon, Charles. The Church of the Holy Sepulchre Jerusalem. London: Oxford University Press, 1974; Conant, Kenneth John. "The Original Buildings at the Holy Sepulchre in Jerusalem». Speculum, 1956, vol. 31, pp. 1-48.

46 Sobre el desplazamiento de materiales vid. TAYLor, Christians and the Holy Places, pp. 113-119. Lo recuerda parcialmente la liturgia hispana de la Inventio crucis (PL, 85, 742).

47 La actividad de Elena es más clara en otras acciones. En 333 se termina de construir sobre una gruta en la que se daba culto a Adonis en Belén un templo dedicado a la Natividad con una basílica de 5 naves. En torno a la cueva se levanta un octógono que sustituía al ábside del edificio. En el Monte de los Olivos, también sobre una cueva, que es donde Cristo se habría reunido con los apóstoles, levanta otro edificio. Eusebio dice que la iglesia se iba a dedicar a la Ascensión que se habría producido en las proximidades.

48 El Gólgota es descrito como monticulus en Itinerarium Burdigalense, 593 (ed. P. Geyer, Itinera Hierosolymitana, Corpus Scriptorum Ecclesiasticorum Latinorum, 39, Viena, 1898).

49 Cripta la llama el Itinerarium Burdigalense, 594, p. 22. 
la cruz y explica que la selección de ese día tenía que ver con el del propio hallazgo de la cruz, además, una fecha que también correspondía con la de la dedicación del templo cristiano. Es probable que la Anástasis se dedicara también el mismo día y, así, se generara un festival cristiano en el que se conmemorara la resurrección el 13 y el 14 se produjera la adoración de la $\mathrm{cruz}^{50}$. Se trataba de una fiesta estrechamente ligada a Jerusalem, pero es probable que se expandiera hacia otras zonas, en la medida que se difundía el culto a la Cruz y la veneración de las reliquias que venían distribuyéndose por todas partes desde esos mismos años ${ }^{51}$.

Estos hallazgos y construcciones se produjeron en época de Constantino, habiendo serias dudas de la participación de Elena en la inventio de la cruz. Un argumento importante en contra del protagonismo de Elena es el silencio de Eusebio que, además, sitúa en dos partes diferenciadas de su obra el hallazgo y la presencia de la madre de Constantino en Jerusalem ${ }^{52}$. El testimonio del Peregrino de Burdeos va en el mismo sentido, puesto que tampoco nos dice nada al respecto, atribuyendo la construcción a Constantino ${ }^{53}$. Sea como fuere originalmente, muy pronto se habría constituido una memoria del hallazgo que otorgaba enorme protagonismo a Elena y, por supuesto, al propio Constantino. En Occidente las referencias de Ambrosio de Milán, Rufino de Aquileya, Sulpicio Severo y Paulino de Nola reforzaron esta percepción ${ }^{54}$.

El protagonismo de Elena se fortaleció. Designada Augusta en 324, había realizado un viaje oriental, un ejemplo que otras mujeres de la familia imperial y de orígenes aristocráticos seguirán. A su regreso a Roma, mandó construir una basílica que aparece en nuestras fuentes como la del palacio Sessoriano, por el antiguo palacio en el que estaba enclavada, o también como basilica Helenae, en donde quedaron depositadas reliquias de la Cruz ${ }^{55}$.

La interpretación de Ambrosio es singular, pues fue él quien alumbró la teoría de la hereditas fidei en la Oración que redactó con ocasión de la muerte de Teodosio (395). Ambrosio, que escribía en el contexto de reforzar los derechos de los herederos de Teodosio,

50 Itin., 48, 1-2

51 Noticias sobre la presencia antigua de reliquias, en Frolow, Anatole. La relique de la vraie croix. Paris: Institut Français d'Études Byzantines, 1961, pp. 158-198.

52 Se ha pensado que su silencio tendría que ver con debilitar al obispo de Jerusalem que quedaría reforzado con la inventio y su vínculo con la familia imperial a través de Elena. Por tanto, el silencio formaría parte del conflicto de Cesarea con Jerusalem y con Macario (Drijvers, Helena Augusta, pp. 85-93).

53 Itinerarium Burdigalense, 594, p. 23. El peregrino burdigalense estuvo en Jerusalem hacia 333. Egeria adopta una actitud intermedia. Sostiene el dinamismo de Constantino, pero ya destaca que se realiza sub praesentia matris suae (Itin. 25, 9).

54 Paulino de Nola. Epistulae, ed. G. de Hartel. Viena: F. Tempsky, 1894, Corpus Scriptorum Ecclesiasticorum Latinorum, vol. 29, 31; Sulpicio Severo. Chronica, ed. C. Halm. Viena: apud G. Geroldi, 1886 , Corpus Scriptorum Ecclesiasticorum Latinorum, vol. 1, II, 33-34).

55 Gesta de Xysti purgatione, 4 (Epistolae Romanorum Pontificum, ed. Pierre Coustant. Parisiis: apud Ludovicum-Dionysium Delatour, 1721, vol. I, app. p. 118). La obra es una falsificación del siglo vi, pero nos transmite adecuadamente la topografía y las denominaciones de ese momento. Hay que ser prudentes, en cambio, con respecto a que este ejemplo influyera directamente en la iglesia de Cangas: su titulación relativa a la cruz -como Santa Croce in Gerusalemme- es de época más tardía, conociéndose en principio por su ubicación en el palatium Sessorianum o como basilica Heleniana o Hierusalem (Drijvers, Helena Augusta, pp. 33-34). No obstante, era sabido que la fundación de Helena conservaba reliquias de la cruz. 
destacaba el papel de los sucesivos nuevos constantinos al frente de un reino cristiano de cuya fe eran garantes. En su propuesta cobra especial protagonismo tanto la difunta esposa de Teodosio como los hijos de este. Teodosio ya había buscado ese paralelismo con Constantino ${ }^{56}$. Su entorno había comparado su victoria del río Frígido con la de Constantino, ambas presentadas como triunfos sobre el paganismo ${ }^{57}$, y el emperador había recuperado el título de Augusta en 383 para su esposa Flacila ${ }^{58}$. En cierto modo, Elena vino a simbolizar el nexo femenino familiar, desde luego reforzando la sucesión dentro del grupo, pero además asumiendo roles relevantes en la construcción de edificios y en el contacto con la sacralidad. El papel de Elena es ocupado por Froiliuba en Cangas, quien quizá aflora en este epígrafe merced a su homologación con la augusta y el reconocimiento de un papel similar, en el que se destacaría el reforzamiento de la legitimidad familiar, su protagonismo en la fundación de la iglesia y su presumible contacto con el ámbito sacral. Es posible que su nombre, más la referencia a sus vástagos, buscara subrayar esa línea sucesoria, frente a otras posibilidades. La ausencia de cualquier mención de Pelayo podría entenderse también en esta misma tesitura.

La iglesia hispana había celebrado la fiesta de la Santa Cruz el día 3 de mayo, como consta en los calendarios tradicionales ${ }^{59}$. Hay una liturgia propia para ese día, pero no existe para el 14 de septiembre, en el que en la tradición hispano-goda se conmemoraba a Cipriano de Cartago. Se celebraba, pues, la conocida como inventio crucis, pero no la exaltatio. En realidad, la aparición de esta fiesta en Occidente fue

56 Hunt, E. David. «Theodosius I and the Holy Land». Studia Patristica, 1997, vol. 29, pp. 52-57.

57 Prudencio en su Contra Symmachum había comparado a Teodosio con Constantino (ed. H. J. Thomson. London: Loeb, 1949, I, pp. 486-488, y II, pp. 712-714) y a la victoria sobre Eugenio en el Frigidus, el 6 de septiembre 394, con la del puente Milvio. En la batalla Rufino había destacado los elementos milagrosos y la había presentado como una victoria sobre el paganismo; vid., también, Agustín DE HipONA, De civitate Dei, V, 26. Orosio había subrayado la importancia de la cruz que, como en el puente Milvio, había precedido a los ejércitos combatientes, mientras que el emperador daba la señal de la batalla con la propia cruz: signo crucis signum proelio dedit... (PAulo Orosio. Historiae, ed. K. Zangemeister. Viena: apud G. Geroldi, 1882, Corpus Scriptorum Ecclesiasticorum Latinorum, vol. 5, VII, 35, 15). Situación que es comparable con lo narrado en el De mortibus persecutorum, en donde, una vez puesto el signum en los escudos, ita proelium commiteret $(44,5)$... Quo signo armatus exercitus capit ferrum $(44,6)$. Los tonos maravillosos de la victoria del Frigidus fueron destacados por Claudiano (Panegyricus de tertio consulatu Honorii, ed. J. Koch, Carmina. Leipzig: Teubner, 1893, p. 106, vv 89-100). Ambrosio había descrito las tropas de Eugenio como exercitus infidelium, reforzando el contenido religioso del enfrentamiento (De obitu Theodosii, 10; PL, 16, col. 1259).

58 Sobre el modelo, vid., Brubaker, Leslie. «Memories of Helena: Patterns in Imperial Female Matronage in the Fourth and Fifth Centuries». En James, Liz (ed.). Women, Men and Eunuchs. Gender in Byzantium. London-New York: Routledge, 1997, pp. 52-75. La designación de Flacila como Augusta ha de interpretarse como modo de reforzar la legitimidad y sucesión de Arcadio (Holum, Kenneth G. Theodosian Empresses: Women and Imperial Dominion in Late Antiquity. Berkeley: University of California Press, 1982, pp. 28-31).

59 Conservamos un himno dedicado a la cruz (Blume, Clemens. Hymnodia gotica. Die mozarabischen Hymnen des alt-spanischen Ritus. Leipzig: O. R. Reisland, 1897, Analecta Hymnica Medii Aevi, vol. 27, n. ${ }^{\circ}$ 38), aunque hay problemas en cuanto a su datación (Szóverffy, Joseph. "Crux fidelis'. Prolegomena to a History of the Holy Cross Hymns». Traditio, 1966, vol. 22, p. 17. El himno (Dulce carmen lingua promat) recoge la tradición del hallazgo por Elena. 
relativamente tardía. Desde Jerusalem debió de trasladarse a otras partes de Oriente ${ }^{60}$. Como fiesta de la Cruz la menciona Alejandro de Chipre ( $†$ 565), quien afirma que se producía "en honor del Padre, del Hijo y del Espíritu Santo" ${ }^{61}$. Se introdujo en Roma en el siglo VII. Al menos el Liber Pontificalis recoge la noticia de que el papa Sergio $(† 701)$ desarrolló el culto a la cruz en la basílica Constantiniana de Roma, en donde se presentaban reliquias de la cruz para su adoración ${ }^{62}$. Es posible que la festividad ya existiera en ese momento y que recibiera un impulso definitivo con las acciones del papa, pero, en cualquier caso, vemos que su desarrollo fue lento en Occidente y que no parece haberse consolidado hasta después del 700.

En un medio en el que esta festividad no se había desarrollado, pudo resultar aceptable una celebración que coincidiera con la victoria de la cruz del puente Milvio. La victoria había venido interpretándose como la de la verdadera fe contra el paganismo $y$, en cualquier caso, contra los enemigos del cristianismo. El templo que se construye habría de testimoniar la victoria con contenido religioso, la legitimidad de la dinastía y el compromiso se haría visible en el culto a la cruz. Además, la iglesia de Cangas se levantaba cuatrocientos ańos más tarde del fallecimiento del emperador Constantino, que había muerto el 22 de mayo del 337. Por tanto, todo un cúmulo de elementos coincidía en una lectura constantiniana y recuperadora de un regnum cristiano que buscaba su modelo en Constantino y su mandato. Es a este referente al que se dirige la mirada y no al pasado peninsular más reciente. El referente político que se visibilizaba era el de un regnum cristiano, emulador del éxito constantiniano.

Cabía entonces construir un templo que implicara un resurgere. La palabra se emplea en alguna rara oportunidad para referirse a la reconstrucción de edificios ${ }^{63}$. Además, significa directamente resurrección ${ }^{64}$ y con este sentido la encontramos empleada en la epigrafía funeraria cristiana ${ }^{65}$. Este significado casa bien con una iglesia que conmemora, como la de Jerusalem, la cruz y la resurrección ${ }^{66}$, en última instancia la victoria de Cristo. Mas tiene también un sentido de renovación espiritual ${ }^{67}$, coincidente con los efectos

60 Su auge tiene que ver con la recuperación de la Cruz por el emperador Heraclio y su entrada triunfante en Jerusalem en marzo del 630. Sin embargo, pronto se transformó el recuerdo de la data en el 14 de septiembre (Frolow, Anatole. «La vraie croix et les expéditions d'Héraclius en Perse». Révue des Études Byzantines, 1953, vol. 11, p. 104). No fue accidental tampoco que la Santa Lanza fuera recibida en Constantinopla el 28 de octubre de 629, después de haber agasajado las reliquias de la Cruz, llegadas el 14 de septiembre (KAEGI, Walter E. Heraclius Emperor of Byzantium. Cambridge: Cambridge University Press, 2003, p. 189). Como vemos, victorias con exaltación religiosa y afirmación del poder buscan los posibles paralelismos con las de Constantino.

${ }^{61}$ Citado por van Tongeren, Louis. Exaltation of the Cross. Toward the Origins of the Feast of the Cross and the Meaning of the Cross in Early Medieval Liturgy. Leuven: Peeters Publishers, 2000, p. 17.

${ }_{62}$ Liber Pontificalis, I, p. 374 (ed. Duchesne, Louis. Le Liber Pontificalis. Texte, introduction et commentaire. Paris: Ernest Thorin Éditeur, 1886).

63 CIL, XI, 00263.

64 Por ejemplo, referido a Lázaro (Io., 11, 23) o al propio Cristo (Mat., 16, 21).

65 Con la fórmula resurget in Christo o similar (CIL, XII, 02058, 02059, 02073).

66 La Anástasis (Resurrección, en griego), también llamada Rotunda, es el templo sobre la tumba de Cristo.

67 Isidoro de Sevilla se refiere a esta resurrección espiritual producto del Espíritu, como cuando los israelíes surgieron -como si de bautismo se tratara- del mar Rojo: Dei populus resurgit renovatus sancto Spiritu (De eccl. officiis, II, 25 (1)). 
de afirmación religiosa que estaban presentes en la tradición constantiniana y que eran parangonables con la victoria de Covadonga. Este resurgir era la renuncia a un pasado no cristiano -quizá representado por el «templo» pagano subyacente- para afirmar una nueva época que habría de instalarse con la nueva monarquía. Mas, sobre todo, es un compromiso que la alusión a los praecepta puede ayudarnos a entender. En la primera línea de la inscripción se alude a unos imprecisos mandatos divinos. Probablemente se refiere al mandato de construir el templo: consurgite, et aedificate sanctuarium Domino Deo (1 Paral., 22, 19), el gran templo destinado al arca de la alianza y núcleo de la naciente monarquía. Además, en los textos bíblicos no son raras las referencias a unos preceptos, que son cumplidos o no por los israelitas, y, en función de esa observancia o custodia, Dios protege o, en caso contrario, castiga a su pueblo. Lo que Fávila y los suyos parecen afirmar es la voluntad de construir el templo y observar esos praecepta y recibir la protección divina ${ }^{68}$. El propio Constantino habría tenido en su favor unos diuina praecepta frente a los superstitiosa maleficia de Majencio y así se había asegurado la victoria ${ }^{69}$. La idea de la redención como victoria de Cristo, en la que la cruz era el trofeo de ese éxito, podría combinarse con una victoria militar en la que se daba protagonismo creciente a la $\mathrm{cruz}^{70}$. En la liturgia hispana del día de la Inventio de la Cruz se recordaba la serie de acontecimientos protagonizados por Cristo, entre los cuales destacaba su resurrección y esta misma palabra se empleaba con un contenido salvífico, pero también superador de un templo pagano que había pretendido la obliteración de la huella cristiana ${ }^{71}$.

La idea era la construcción de una nueva Jerusalem, un proyecto difícilmente desligable de las profecías bíblicas y del sentimiento apocalíptico. El resurgir del templo era el eje central de la profecía de Ezequiel, núcleo central de la nueva ciudad. La idea estaba también presente en el Apocalipsis, aunque con un sentido menos material, aludiendo a un nuevo reino que desciende de los cielos ${ }^{72}$. Todo este desarrollo venía a sugerir una nueva era, con un nuevo Constantino al frente y un sentido de renovación religiosa y política. Probablemente se conjugaba, además, con el sentimiento del fin de la sexta edad. El proyecto, finalmente, ha de entenderse dentro de uno más amplio que daba nuevo lustre a Cangas, como sede de un nuevo reino.

Díaz y Díaz señaló algunos de los precedentes literarios de los versos de la inscripción de la Santa $\mathrm{Cruz}^{73}$. A nosotros nos interesa revelar cierto paralelismo con algunas

68 Quizá muy directamente en el sentido de Ex., 15, 26. Entre ellos poseer la tierra deseada, Deut., 4, 1; 4, 40. Quizá había un sentido personal, referido específicamente a un monarca que iniciaba su reinado (3 Reg., 3, 14). Hay que tener en cuenta que Salomón vuelve a recibir la promesa en el contexto de la construcción del templo (3 Reg., 6, 11-13 y 9, 4-7).

69 Paneg., IX, 4, 4 (Mynors, R. A. B.; Nixon, C. E. V. y Rodgers, Barbara S. (eds.). In Praise of Later Roman Emperors: The Panegyrici Latini. Berkeley: University of California Press, 1994, p. 596). La leyenda desarrollaría luego esos preceptos cumplimentados por el emperador.

70 Hemos de tener presente que, en la elaboración cronística, el protagonismo recae en la advocación mariana de Covadonga (Rot., 10). No aparece ninguna referencia a la cruz.

71 Recordando la construcción del templo en aquellos lugares: si in his locis idola colerentur: in quibus Christus natus est: ut pateretur: passus est: ut resurgeret. Surrexit: ut regnaret... (PL, 85, col. 742).

72 Apoc., 22, 1-20.

73 Señala influencias de Draconcio y de Venancio Fortunato. 
AMANCIO ISLA FREZ

EL REY FÁVILA, LA REINA FROILIUBA Y LA FUNDACIÓN DE LA IGLESIA DE SANTA CRUZ DE CANGAS (737)

inscripciones de San Pedro del Vaticano ${ }^{74}$. En San Pedro de Roma la cruz donada por Constantino parece haber llevado los nombres de los dos donantes, Constantino y su madre Elena. Además, en el arco triunfal de la basílica una bien conocida inscripción señalaba: QUOD DUCE TE MUNDUS SURREXIT IN ASTRA TRIUMPHANS HANC CONSTANTINUS VICTOR TIBI CONDIDIT AULAM ${ }^{75}$. El epígrafe tiene resonancias en nuestro: EC AULA... FAFFILA SIC CONDIDIT. Aunque no demos especial capacidad probatoria a estas similitudes, parece que quienes llevaron a cabo el proyecto de la Santa Cruz, buscaron desarrollar el paralelismo de Fávila con la epigrafía imperial de Constantino, ambos servidores de la cruz y con ella victoriosos. El referente de Elena era sustituido por Froiliuba. Su presencia aquí no solo cubría esa necesidad de un personaje femenino, sino que pretendía, sobre todo, reforzar la legitimidad de la familia regia y, en concreto, de esta línea sucesoria. Al participar en la actividad fundadora, Froiliuba adquiría un tono cercano al de Elena ${ }^{76}$. Es probable que este elemento fuera de importancia política notable en el contexto de la corte astur, muy poco después de la muerte de Pelayo. El sucesor directo de Pelayo se vio en la necesidad de consolidar su legitimidad regia, interpretando los acontecimientos de los últimos ańos y explicando lo que era el reino recién constituido.

\section{REFERENCIAS BIBLIOGRÁFICAS}

Aurelio Víctor. De Caesaribus, ed. Franz Pichlmayr. Leipzig: Teubner, 1983 reimp.

Barbero, Abilio y Vigil, Marcelo. La formación del feudalismo en la Peninsula Ibérica. Barcelona: Crítica, 1978.

Blume, Clemens. Hymnodia gotica. Die mozarabischen Hymnen des alt-spanischen Ritus. Leipzig: O. R. Reisland, 1897.

Brubaker, Leslie. «Memories of Helena: Patterns in Imperial Female Matronage in the Fourth and Fifth Centuries». En James, Liz (ed.). Women, Men and Eunuchs. Gender in Byzantium. London-New York: Routledge, 1997, pp. 52-75.

Cameron, Averil y Hall, Stuart. Eusebius, Life of Constantine. Oxford: Clarendon Press, 1999.

Carvallo, Luis Alfonso de. Antigüedades y cosas memorables del principado de Asturias. Madrid: por Julián de Paredes, 1695.

Caveda y Nava, José. Ensayo histórico sobre los diversos géneros de arquitectura empleados en España desde la dominación romana hasta nuestros días. Madrid: Imprenta de Santiago Saunaque, 1848.

Conant, Kenneth John. «The Original Buildings at the Holy Sepulchre in Jerusalem». Speculum, 1956, vol. 31, pp. 1-48.

CoüAsnon, Charles. The Church of the Holy Sepulchre Jerusalem. London: Oxford University Press, 1974.

74 La basílica se levanta sobre un templo de Apolo (Liber Pontificalis, Vita Sylv. XXXIV, 16, ed. Duchesne, I, p. 176). Glen W. Bowersock ha tratado de debilitar el nexo de la iglesia vaticana con Constantino, a pesar de las referencias textuales y epigráficas (Bowersock, Glen W. «Peter and Constantine». En Tronzo, William (ed.). St. Peter's in the Vatican. Cambridge: Cambridge University Press, 2005, pp. 5-15).

75 ICUR-02, 04092 = ILCV 01752. En la cruz podía leerse: CONSTANTINUS AUGUSTUS ET HELENA AUGUSTa [...] haNC DOMUM Regalem Simile fulgore CORUSCANS AUla Circumdat (Liber Pontificalis, I, 176).

76 No importa en este sentido que fuera la esposa de Fávila. Recuérdese cómo en los versos laudatorios escritos por Venancio Fortunato a Justino II y su esposa Sofía, aquel era comparado con Constantino y esta con Elena (Ad Justinum, 67; ed. F. Leo, MGH, AA, IV/1, p. 277). 
DíAz y DíAz, Manuel C. «La inscripción de Cangas de Onís». En Asturias en el siglo viII: la cultura literaria. Oviedo: Sueve, 2001, p. 32.

DíAz y DíAz, Manuel C. «La lengua institucional en la Hispania de los siglos VI-XI». En Ideologie e pratiche del reimpiego nell'Alto Medievo. Spoleto: Centro Italiano di Studi sull'Alto Medioevo, 1999 , pp. 435-458.

DíAz y DíAz, Manuel C. "Más sobre epítetos regios en la Hispania visigoda». Studi Medievali, 1978, vol. XIX, pp. 317-333.

Díaz y Díaz, Manuel C. "Titulaciones regias en la monarquía visigoda». Revista Portuguesa de Història, 1978, vol. XVI, pp. 133-141.

Diego Santos, Francisco. Inscripciones medievales de Asturias. Oviedo: Consejería de Educación, Cultura, Deportes y Juventud, 1994.

Digeser, Elizabeth DePalma. The Making of a Christian Empire. Lactantius and Rome. Ithaca: Cornell University Press, 2000.

Drake, Harold A. Constantine and the Bishops. The Politics of Intolerance. Baltimore: Johns Hopkins University Press, 2002.

Drijvers, Jan Willem. Helena Augusta. The Mother of Constantine the Great and the Legend of Her Founding of the True Cross. Leiden: Brill, 1992.

Duchesne, Louis. Le Liber Pontificalis. Texte, introduction et commentaire. Paris: Ernest Thorin Éditeur, 1886.

Epistolae Romanorum Pontificum, ed. Pierre Coustant. Parisiis: apud Ludovicum-Dionysium Delatour, 1721.

Eusebius Werke, ed. de Eduard Schwartz y Theodor Mommsen. Leipzig: J. C. Hinrich'sche Buchhandlung, 1908.

Fernández Conde, F. Javier. «Lugares de culto en Asturias durante la época de la transición». Asturiensia Medievalia, 1993-1994, vol. 7, pp. 31-55.

Fernández Conde, Javier. La religiosidad medieval en España. Alta Edad Media (siglos VII-X). Oviedo: Universidad de Oviedo, 2000.

Fernández-Guerra, Aureliano. El libro de Santoña. Madrid: Imprenta de Manuel Tello, 1872.

Frolow, Anatole. "La vraie croix et les expéditions d'Héraclius en Perse». Révue des Études Byzantines, 1953, vol. 11, p. 104.

Frolow, Anatole. La relique de la vraie croix. Paris: Institut Français d'Études Byzantines, 1961.

García de Castro, César. Arqueología cristiana de la Alta Edad Media en Asturias. Oviedo: Real Instituto de Estudios Asturianos, 1995.

Garibay, Esteban de. Compendio historial. Barcelona: por Sebastián de Cormellas, 1628.

GiL, Juan (ed.). Crónicas asturianas. Oviedo: Servicio de Publicaciones, Universidad de Oviedo, 1985.

GiL, Juan. «Los terrores del año 800». En Actas del Simposio para el estudio de los códices del "Comentario al Apocalipsis» de Beato de Liébana. Madrid: Joyas Bibliográficas, 1978, vol. I, pp. 217-247.

Heim, François. «L'influence exercée par Constantin sur Lactance: sa théologie de la victoire». En Fontaine, Jacques y Perrin, Michel (eds.). Lactance et son temps. Recherches actuelles. Paris: Beauchesne, 1978, pp. 55-74.

Hollerich, Michael J. "The Comparison of Moses and Constantine in Eusebius of Caesarea's Life of Constantine». Studia Patristica, 1989, vol. 19, pp. 80-85.

Holum, Kenneth G. Theodosian Empresses: Women and Imperial Dominion in Late Antiquity. Berkeley: University of California Press, 1982.

Hunt, E. David. «Theodosius I and the Holy Land». Studia Patristica, 1997, vol. 29, pp. 52-57. 
AMANCIO ISLA FREZ

EL REY FÁVILA, LA REINA FROILIUBA Y LA FUNDACIÓN DE LA IGLESIA

DE SANTA CRUZ DE CANGAS (737)

IsLA Frez, Amancio. «El adopcionismo y las evoluciones religiosas y políticas en el reino astur». Hispania, 1998, vol. 58, n. ${ }^{\circ}$ 200, pp. 971-993.

Kaegi, Walter E. Heraclius Emperor of Byzantium. Cambridge: Cambridge University Press, 2003.

Lactancio, Lucio C. Divinae Institutiones, ed. S. Brandt. Viena: F. Tempsky, 1890.

Lambert, A. «Astère». En Dictionnaire d'Histoire et de Géographie ecclésiastiques. Paris: Letouzey et Ané, 1930, vol. IV, pp. 1164-1165.

Martínez Villa, Alberto. "La necrópolis medieval de la ermita de Santa Cruz (Cangas de Onís)». En III Congreso de Arqueología Medieval Española. Madrid: Asociación Española de Arqueología Medieval, 1989, vol. II, pp. 155-160.

Morales, Ambrosio de. Corónica general de España. Madrid: en la oficina de don Benito Cano, 1791.

Morales, Ambrosio de. Viage... a los reinos de León y Galicia y Principado de Asturias, ed. de Enrique Flórez. Madrid: por Antonio Marín, 1765.

Moreau, Jacques. Lactance. De la mort des persécuteurs. Paris: Éditions du Cerf, 1954.

Mynors, R. A. B.; Nixon, C. E. V. y Rodgers, Barbara S. (eds.). In Praise of Later Roman Emperors: The Panegyrici Latini. Berkeley: University of California Press, 1994.

Paulino de Nola. Epistulae, ed. G. de Hartel. Viena: F. Tempsky, 1894.

Paulo Orosio. Historiae, ed. K. Zangemeister. Viena: apud G. Geroldi, 1882.

Prudencio. Contra Symmachum, ed. H. J. Thomson. London: Loeb, 1949.

Ríos González, Sergio. "Excavaciones arqueológicas en la iglesia de Santa Eulalia de Abamia (Cangas de Onís), 2005-2006». En Excavaciones arqueológicas en Asturias. Oviedo: Gobierno del Principado de Asturias, 2009, pp. 201-208.

Sulpicio Severo. Chronica, ed. C. Halm. Viena: apud G. Geroldi, 1886.

Szóverffy, Joseph. «Crux fidelis'. Prolegomena to a History of the Holy Cross Hymns». Traditio, 1966, vol. 22, p. 17.

TAYLOR, Joan. Christians and the Holy Places. Myth of Jewish-Christian Origins. Oxford: Clarendon Press, 1993.

van Tongeren, Louis. Exaltation of the Cross. Toward the Origins of the Feast of the Cross and the Meaning of the Cross in Early Medieval Liturgy. Leuven: Peeters Publishers, 2000.

Vega del Sella, Ricardo [Duque de Estrada y Martínez de Morentín]. El dolmen de la capilla de Santa Cruz (Asturias). Madrid: Museo Nacional de Ciencias Naturales, 1919.

Vigil, Ciriaco M. Asturias monumental, epigráfica y diplomática. Oviedo: Hospicio, 1887.

Vives, José. Inscripciones cristianas de la España romana y visigoda. Barcelona: Consejo Superior de Investigaciones Científicas, 1942.

von Soden, Hans. Urkunden zur Entstehungeschichte der Donatismus. Bonn: Markus \& Weber, 1903. 
